\title{
Three-dimensional printing and neuroendovascular simulation for the treatment of a pediatric intracranial aneurysm: case report
}

\author{
*Sean Sullivan, BS, ${ }^{1}$ Pedro Aguilar-Salinas, MD, ${ }^{1}$ Roberta Santos, MD, ${ }^{1}$ Alexandra D. Beier, DO, ${ }^{2}$ \\ and Ricardo A. Hanel, MD, PhD'
} 'Lyerly Neurosurgery, Baptist Neurological Institute; and ²Division of Pediatric Neurosurgery, University of Florida Health Science
Center, Jacksonville, Florida

\begin{abstract}
The use of simulators has been described in a variety of fields as a training tool to gain technical skills through repeating and rehearsing procedures in a safe environment. In cerebrovascular surgery, simulation of skull base approaches has been used for decades. The use of simulation in neurointervention to acquire and enhance skills before treating a patient is a newer concept, but its utilization has been limited due to the lack of good models and deficient haptics. The advent of 3D printing technology and the development of new training models has changed this landscape. The prevalence of aneurysms in the pediatric population is much lower than in adults, and concepts and tools sometimes have to be adapted from one population to another. Neuroendovascular rehearsal is a valid strategy for the treatment of complex aneurysms, especially for the pediatric population. The authors present the case of an 8-year-old boy with a fusiform intracranial aneurysm and documented progressive growth, who was successfully treated after the authors rehearsed the placement of a flow diverter using a patient-specific 3D-printed replicator system model.
\end{abstract}

https://thejns.org/doi/abs/10.3171/2018.6.PEDS17696

KEYWORDS aneurysm; flow diverter; intervention; simulation; 3D printing; vascular disorders

$\mathrm{F}$ OR many years simulation has been used in a variety of fields, from aviation to general surgery, as a training tool to gain technical skills through repetition while also rehearsing procedures in a safe environment. ${ }^{12,17}$ The use of simulation in neurointervention to acquire and enhance skills before treating a patient is more recent, but the lack of good models and deficient haptics have limited its utilization. The advent of 3D printing technology and the development of new training models have modified this landscape. The use of simulation in neuroendovascular training has been shown to result in shorter fluoroscopy times, better acquisition of roadmaps, and useful angiographic projections. ${ }^{11}$

The prevalence of aneurysms in the pediatric population is much lower than in adults, and concepts and tools sometimes have to be adapted from one population to another. Simulation technologies allow neurointerventionalists to practice a procedure in a safe environment before treating a more vulnerable pediatric patient, especially in the setting of a complex vascular lesion. ${ }^{4}$ Additionally, the simulation allows the operator to better select tools for the procedure, possibly reducing the radiation dose (which is even more critical in pediatric patients) as well as detecting pitfalls for the selected devices in a risk-free environment. In this paper we present the case of a pediatric patient with a dissecting intracranial aneurysm (IA) who was treated after we rehearsed the placement of a flow diverter using a patient-specific 3D-printed replicator system model.

\section{Case Report}

History and Examination

An 8-year-old boy, with a history of treatment for a dissecting posterior wall aneurysm in the right internal carotid artery (ICA) using coil embolization and flow diversion, over 3 years of follow-up developed a fusiform aneurysm of the supraclinoid segment of the left ICA with a saccular component and documented growth on serial imaging. The patient was initially going to be treated with off-label use of a Pipeline embolization device (ev3, Covidien), but

ABBREVIATIONS IA = intracranial aneurysm; ICA = internal carotid artery; $M C A=$ middle cerebral artery.

SUBMITTED December 11, 2017. ACCEPTED June 13, 2018.

INCLUDE WHEN CITING Published online September 14, 2018; DOI: 10.3171/2018.6.PEDS17696.

* S.S. and P.A.S. contributed equally to this work. 

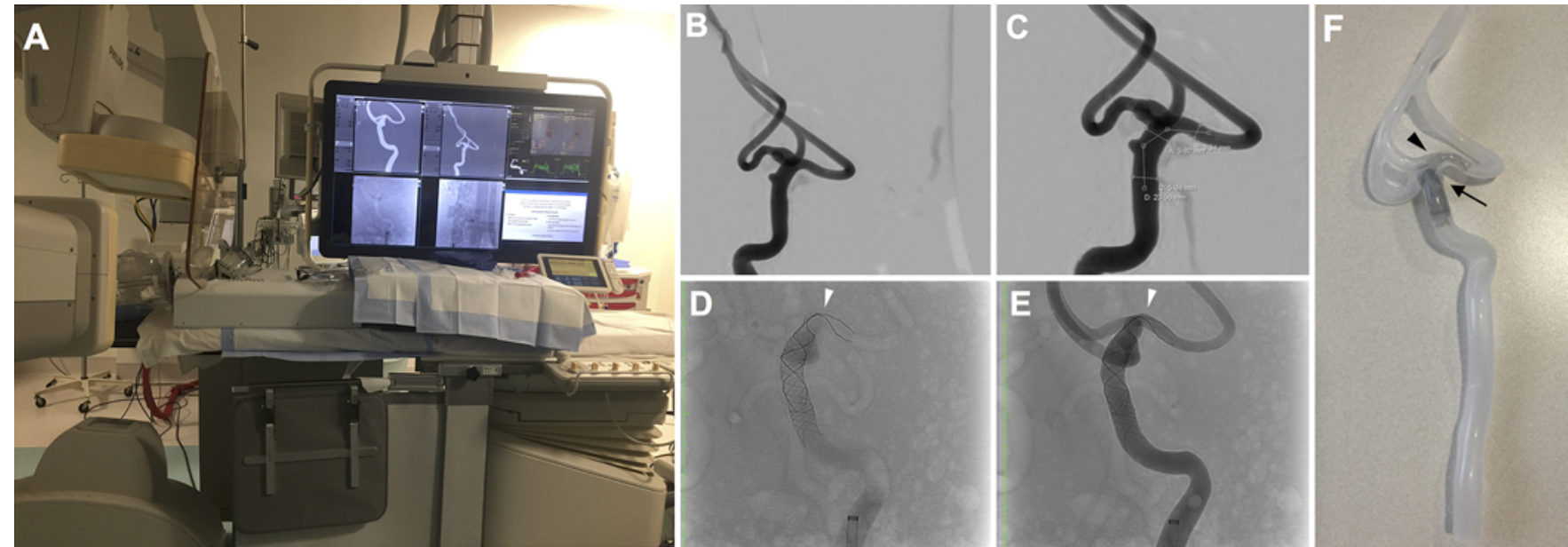

FIG. 1. A: Patient-specific replicator system model of the patient's cerebral vasculature set up in the angiography suite. B and C: Angiographic oblique images of the silicone vessels after injecting contrast, depicting the fusiform aneurysm with a saccular component in the ICA. D and E: A Leo+ stent was deployed from the left MCA to the proximal segment of the ICA, and later, a SILK flow diverter was telescoped. The final construct did not properly expand (arrowhead) due to mismatch of the MCA-ICA and the sharp curvature of the MCA. F: 3D-printed silicone vessel demonstrating the sidewall aneurysm of the ICA (arrow) and the final construct kinking in the proximal segment of the MCA (arrowhead). Figure is available in color online only.

the procedure was aborted due to the increase in size of the parent vessel, measuring $6 \mathrm{~mm}$ at the largest diameter. After considering numerous treatment options, it was decided that the parent vessel was too large for any flow diverter available in the US, and that clip placement was not ideal due to the likely dissecting nature of the lesion. Therefore, we believed the patient would benefit from the SILK flow diverter device (Balt Extrusion). We received US FDA and local IRB approvals for a compassionate use exemption for the off-label use of the SILK flow diverter.

\section{Three-Dimensional Printing and Simulation}

Using source imaging from the most recent cerebral angiogram, the target lesion and target vessel were 3D printed using a replicator system model (Vascular Simulations) of the patient's cerebral vasculature (Fig. 1). Two strategies were rehearsed and compared using the replicator model: 1) a standalone construct with the SILK device extending from the ICA terminus to the ophthalmic segment, versus 2) a dual-device construct using the Leo+ stent (Balt Extrusion) and the SILK flow diverter. The Leo+ was deployed from the left proximal middle cerebral artery (MCA) to the ICA, and the SILK device was solely telescoped into the stented segment of the left ICA to cover the saccular component of the aneurysm. On careful inspection of the dual-device construct (Leo+ and SILK), we noticed a lack of ideal expansion of the Leo+ device in the ICA terminus due to the sharp curvature and diameter mismatch of that segment to the more proximal carotid artery (Fig. 1D-F). Therefore, the patient was treated with the strategy developed during the simulation using the SILK flow diverter only, beginning proximal to the tortuous segment.

\section{Operative Course}

The patient was previously placed on dual antiplatelet therapy (81 $\mathrm{mg}$ of aspirin daily and $1 \mathrm{mg} / \mathrm{kg}$ of clopidogrel daily) and VerifyNow (Accriva Diagnostics) therapeutic levels were obtained prior to the procedure. A right femoral artery access was obtained with a 6-Fr Glidesheath Slender catheter (Terumo Interventional Systems) and the patient was given a single $50 \mathrm{U} / \mathrm{kg}$ dose of intravenous heparin intraoperatively. The initial angiogram and a 3D reconstruction demonstrated the sidewall aneurysm in the left supraclinoid ICA (Fig. 2A-D). A Neuron 0.70-inch guide catheter (Penumbra) was placed into the left ICA. Subsequently, a Vasco+ 25 microcatheter (Balt Extrusion) was advanced over a microwire to the target vessel and navigated past the left ICA aneurysm, into the distal left MCA. The microwire was removed and a SILK device $(5.5 \times 25 \mathrm{~mm})$ was advanced into the microcatheter. Due to the kinking observed during the simulator rehearsal, we decided to deploy the SILK device extending from the ICA terminus to the ophthalmic segment. The device was deployed uneventfully and crossed the entirety of the aneurysm neck (Fig. 2E-G). Angioplasty with a Hyperform balloon $(7 \times 7 \mathrm{~mm}$; Medtronic) was performed to improve the apposition of the SILK device. A cone-beam CT angiogram demonstrated good wall apposition of the device without parent vessel compromise (Fig. 2H and I).

\section{Postoperative Course and Follow-Up}

At the 6-month follow-up, the patient was neurologically intact but complaining of recurrent mild headaches with a modified Rankin Scale score of 1. CT angiography demonstrated patency of the left ICA and good position of the flow diverter (Fig. 2J-L). The 6-month imaging follow-up demonstrated aneurysm occlusion and patency of the left ICA (Fig. 2M). The patient will undergo a cerebral angiogram at the 1-year follow-up.

\section{Discussion}

Pediatric IAs account for less than 5\% of aneurysms 

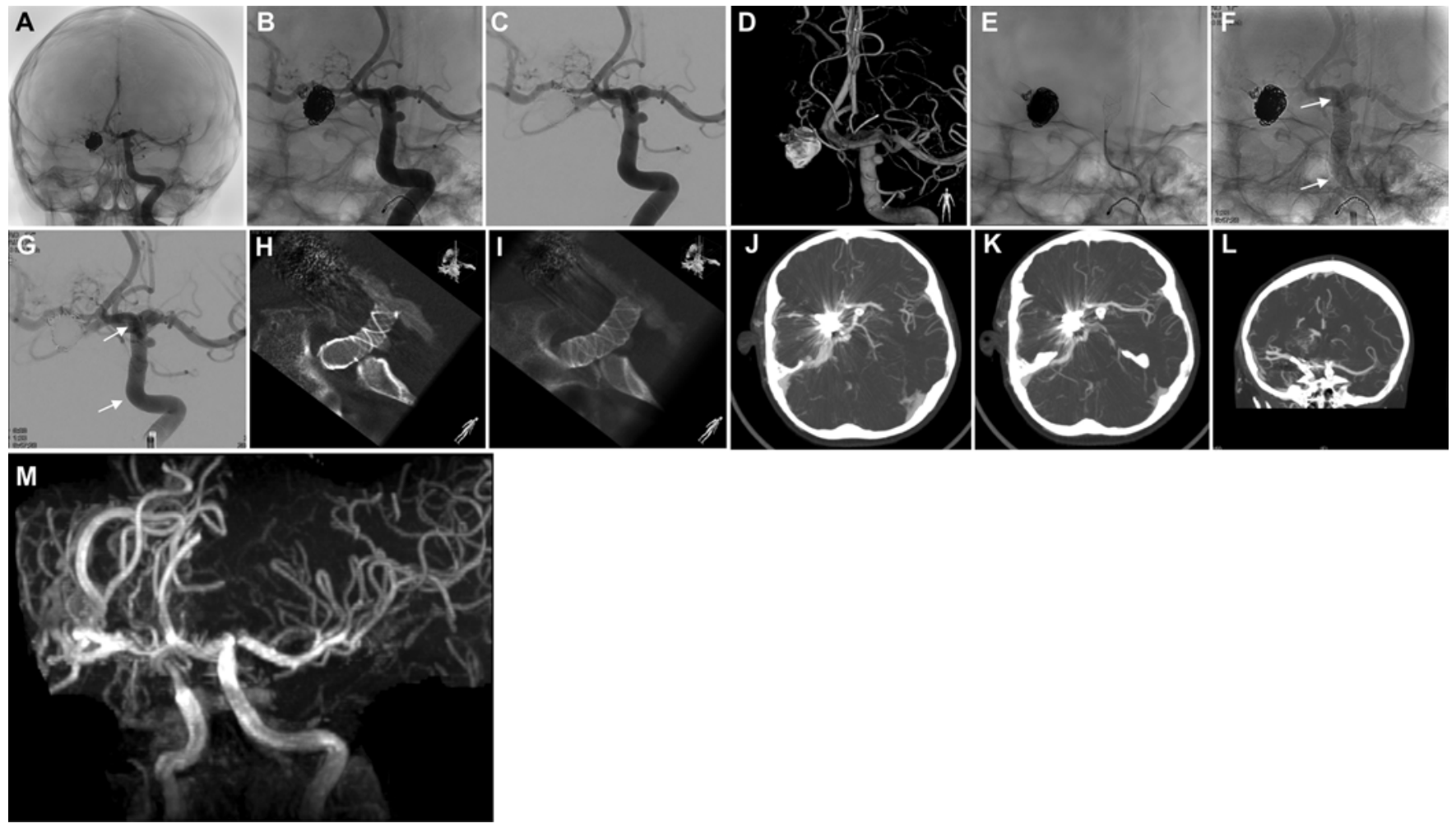

FIG. 2. A-C: Cerebral angiogram, anteroposterior $(A)$ and oblique views ( $B$ and $C$ ), demonstrating the sidewall aneurysm arising from the ICA. D: 3D reconstruction depicting the aneurysm in the left ICA and the previously coiled lesion in the contralateral side. Treatment was performed using the SILK device from the ICA terminus downward, covering the aneurysm neck. E-G: The SILK device partially deployed (E) and a fluoroscopic image (F) demonstrating the placement of the flow diverter (arrows). A final angiographic run demonstrated patency of the left ICA as well as its branches (G). H and I: A cone-beam CT scan was performed demonstrating good wall apposition of the device. J-L: At the 3-month follow-up, CT angiography was performed showing a stable location of the SILK device, no evidence of the aneurysm, and patency of the left ICA and its branches. M: At the 6-month imaging follow-up, MR angiography demonstrated complete occlusion of the left ICA aneurysm.

found in the general population. ${ }^{1}$ These lesions differ from adult aneurysms in location and size, but overall, they tend to be more complex in morphology (giant, wide neck, dissecting). ${ }^{20}$ Treatment modalities used for adult aneurysms can be applied to the pediatric population but special considerations have to be made, in particular the size of endovascular devices and longer life expectancy with a latent risk of recurrence or de novo IA formation.

Rehearsing the intervention can decrease procedural time, radiation dose, and possible complications. In our case, the use of a simulator allowed us to gain a comfort level using a novel device, on an exact replica of our patient's aneurysm, in a risk-free environment before performing the procedure. The use of the replicator also allowed us to detect performance issues with one of the devices due to an unanticipated tortuosity and size mismatch that was not appreciated on careful preoperative image analysis.

Vascular simulation has been shown to improve the skills of not only novice neurointerventionalists but also experienced operators and fellows. However, there are several types of simulators to choose from, each with its own advantages and disadvantages (Table 1). The virtual reality models allow one to rehearse a large variety of scenarios as well as the ability to upload a patient's radiographic information to create a patient-specific scenario. Neverthe- less, they can be expensive and have been noted to lack accurate haptic feedback. ${ }^{5}$ Human cadavers provide accurate anatomy, and when combined with pump-driven flow models, this model provides useful simulation of the conditions of live surgery for clipping aneurysms and management of complications such as intraoperative rupture. ${ }^{16}$ Another option is to use ex-vivo models such as a human placenta, in which aneurysms can be developed, multiple surgical scenarios simulated, and complication management practiced..$^{15,18}$ The benefits of using human placenta include low cost, ready accessibility, and most importantly, realistic haptic feedback. ${ }^{3}$ Nonetheless, ex-vivo models are not able to simulate specific patient vasculature. Pumpdriven flow models with silicone vessels, like the one we used, are advantageous in that they allow direct visualization of the wire, catheter, and devices as well as the ability to use patient-specific vasculature. ${ }^{4}$ The drawbacks include limited haptic feedback and the fixed vascular anatomy of this model. Although surgical simulation is not novel and is greatly accepted for training residents or improving specific surgical skills, only a few studies have been reported that involved rehearsing a patient's cerebrovascular lesion operation before the actual surgery (Table 2). In fact, the majority of these studies have compared the preplanned procedure to the actual surgery for aneurysm clip- 
TABLE 1. Summary of types of simulations available for cerebrovascular surgery

\begin{tabular}{|c|c|c|}
\hline Simulation & Advantages & Disadvantages \\
\hline Virtual reality & $\begin{array}{l}\text { Simulation of replicated patient-specific lesions } \\
\text { Durability } \\
\text { Multiple models \& metrics } \\
\text { Minimal risks }\end{array}$ & $\begin{array}{l}\text { Low to intermediate fidelity } \\
\text { Low to intermediate haptic \& force feedback } \\
\text { Maintenance }\end{array}$ \\
\hline $\begin{array}{l}\text { 3D printed } \\
\text { vessel }\end{array}$ & $\begin{array}{l}\text { Simulation of replicated patient-specific lesions } \\
\text { Minimal risks } \\
\text { Acceptable haptics for endovascular simulation }\end{array}$ & $\begin{array}{l}\text { Cost (depending on material) } \\
\text { Durability (one to a few times depending on material) } \\
\text { Maintenance } \\
\text { Time of fabrication } \\
\text { Different elasticity response compared to real arteries }\end{array}$ \\
\hline $\begin{array}{l}\text { Human } \\
\text { cadaver }\end{array}$ & $\begin{array}{l}\text { Human tissue } \\
\text { Approximate reality } \\
\text { High fidelity (dissection, bypass) } \\
\text { Minimal risks }\end{array}$ & $\begin{array}{l}\text { High cost } \\
\text { Unable to reproduce patient-specific lesions for preop simulation } \\
\text { Maintenance } \\
\text { Single use }\end{array}$ \\
\hline Live animals & $\begin{array}{l}\text { Minimal risks } \\
\text { High fidelity (hemostasis, dissection, bypass) }\end{array}$ & $\begin{array}{l}\text { High cost } \\
\text { Unable to reproduce patient-specific lesions for preop simulation } \\
\text { Maintenance } \\
\text { Single use }\end{array}$ \\
\hline $\begin{array}{l}\text { Ex-vivo (e.g., } \\
\text { human } \\
\text { placenta) }\end{array}$ & $\begin{array}{l}\text { Low cost } \\
\text { Minimal risks } \\
\text { High fidelity (hemostasis, dissection, clipping, bypass, endovascular) } \\
\text { Multiple uses }\end{array}$ & Unable to reproduce patient-specific lesions for preop simulation \\
\hline
\end{tabular}

TABLE 2. Summary of studies reporting surgical outcomes following preoperative simulation for aneurysm treatment

\begin{tabular}{|c|c|c|c|c|c|}
\hline $\begin{array}{l}\text { Authors } \\
\text { \& Year }\end{array}$ & $\begin{array}{l}\text { Study } \\
\text { Design }\end{array}$ & Simulation Model & $\begin{array}{c}\text { Type of } \\
\text { Intervention }\end{array}$ & $\begin{array}{c}\text { No. of } \\
\text { Aneurysms }\end{array}$ & Outcomes/Comments \\
\hline $\begin{array}{l}\text { Duckworth et } \\
\text { al., } 2015\end{array}$ & $\begin{array}{l}\text { Case } \\
\text { report }\end{array}$ & $\begin{array}{l}\text { 3D printed vessel/ } \\
\text { pump-driven flow }\end{array}$ & $\begin{array}{l}\text { Flow diverter } \\
\text { deployment }\end{array}$ & 1 & $\begin{array}{l}\text { Use of new technology; improved technical approach for the real } \\
\text { intervention }\end{array}$ \\
\hline $\begin{array}{l}\text { Ishibashi et } \\
\text { al., } 2016\end{array}$ & $\begin{array}{l}\text { Case } \\
\text { series }\end{array}$ & 3D-printed vessel & $\begin{array}{l}\text { Coiling/microcath- } \\
\text { eter navigation }\end{array}$ & 27 & $\begin{array}{l}\text { Preplanned microcatheter shaping was good in terms of accessibility, } \\
\text { positioning, \& stability; no specific data on patient outcomes }\end{array}$ \\
\hline $\begin{array}{l}\text { Kimura et al., } \\
2009\end{array}$ & $\begin{array}{l}\text { Case } \\
\text { series }\end{array}$ & $\begin{array}{l}\text { 3D-printed hollow } \\
\text { elastic model }\end{array}$ & Surgical clipping & 8 & $\begin{array}{l}4 \text { of } 8 \text { interventions performed w/ same preop strategy; residual neck } \\
\text { in } 2 \text { patients at last follow-up }\end{array}$ \\
\hline $\begin{array}{l}\text { Kono et al., } \\
2013\end{array}$ & $\begin{array}{l}\text { Case } \\
\text { report }\end{array}$ & 3D-printed vessel & $\begin{array}{l}\text { Balloon-assisted } \\
\text { coiling }\end{array}$ & 1 & $\begin{array}{l}\text { Improvement in microcatheter navigation w/ the simulation; little } \\
\text { discrepancy in strategy; successful treatment of the aneurysms }\end{array}$ \\
\hline $\begin{array}{l}\text { Marinho et } \\
\text { al., } 2014\end{array}$ & $\begin{array}{l}\text { Case } \\
\text { series }\end{array}$ & Virtual reality & Surgical clipping & 10 & $\begin{array}{l}\text { All aneurysms occluded; same surgical strategy in } 8 \text { of } 10 \text { aneu- } \\
\text { rysms; } 1 \text { patient had postop seizures }\end{array}$ \\
\hline $\begin{array}{r}\text { Mashiko et } \\
\text { al., } 2015\end{array}$ & $\begin{array}{l}\text { Case } \\
\text { series }\end{array}$ & $\begin{array}{l}\text { 3D-printed hollow } \\
\text { elastic model }\end{array}$ & Surgical clipping & 20 & $\begin{array}{l}\text { Better understanding of the vessel anatomy; } 12 \text { of } 20 \text { replicated } \\
\text { aneurysms were clipped; } 3 \text { were endovascularly managed; } 4 \text { were } \\
\text { not treated \& } 1 \text { patient died before surgery; unexpected findings: } \\
\text { hard wall or tissue adhesion; preplanned clipping strategy varied } \\
\text { minimally to actual intervention }\end{array}$ \\
\hline $\begin{array}{l}\text { Namba et al., } \\
2015\end{array}$ & $\begin{array}{l}\text { Case } \\
\text { series }\end{array}$ & 3D-printed vessel & $\begin{array}{l}\text { Coiling/microcath- } \\
\text { eter navigation }\end{array}$ & 10 & $\begin{array}{l}\text { Successful microcatheter navigation as the preplanned strategy; } 1 \\
\text { complication, vessel injury }\end{array}$ \\
\hline $\begin{array}{l}\text { Shono et al., } \\
2018\end{array}$ & $\begin{array}{l}\text { Case } \\
\text { series }\end{array}$ & Virtual reality & Surgical clipping & 8 & $\begin{array}{l}5 \text { of } 8 \text { procedures were performed as the preplanned strategy; } \\
\text { challenges: shorter parent vessel, calcification, bleb, thrombosed } \\
\text { lesion }\end{array}$ \\
\hline $\begin{array}{l}\text { Wang et al., } \\
2017\end{array}$ & $\begin{array}{l}\text { Case } \\
\text { series }\end{array}$ & $\begin{array}{l}\text { 3D-printed cranio- } \\
\text { vascular model }\end{array}$ & Surgical clipping & 6 & $\begin{array}{l}\text { Little discrepancy on the preplanned surgical strategy; improved } \\
\text { understanding of the surgical view }\end{array}$ \\
\hline $\begin{array}{l}\text { Wang et al., } \\
2018\end{array}$ & $\begin{array}{l}\text { Case } \\
\text { series }\end{array}$ & 3D-printed vessel & Surgical clipping & 8 & $\begin{array}{l}\text { Similar strategy performed in the actual surgery; strategy (e.g., more } \\
\text { clips) usually changed because of hard wall or wide-necked lesion }\end{array}$ \\
\hline
\end{tabular}


ping 7,9,10,19,21,22 and endovascular management; these studies have mainly assessed microcatheter vascular access or endosaccular embolization. ${ }^{6,8,13}$ In general, the results of the above studies suggest that the preplanned strategy is usually performed in the actual procedure and the benefits are perceived by the operator, however, there is no consensus on how to objectively measure outcomes after simulation and there is no prediction of the long-term outcome for the patient. Also, in some instances such as aneurysm rupture, it is futile to consider performing a surgical simulation.

To date, there is no standard of treatment for pediatric aneurysms and flow diversion has been demonstrated to be a safe and effective alternative. ${ }^{2,14}$ However, these patients require close monitoring because they are placed on dualantiplatelet therapy and are exposed to potential delayed events that can occur after using a flow diverter well described in the adult population. ${ }^{23}$ In our case, the decision to treat the aneurysm was made based on progression of the lesion and the use of a flow diverter was considered the most appropriate choice, given the lack of good microsurgical and endovascular options.

Three-dimensional printing and neuroendovascular simulation should be considered as strategies for the training of new operators and the implementation of new technologies and endovascular tools. This can also be used in select complex cases in which patient-specific models can decrease procedural times, number of devices used, and potential complications. The complex and rare nature of some pediatric aneurysms gives reason to consider utilizing this strategy before undertaking such a procedure. Thus, multiple approaches and various devices can not only be considered, but also tested before having the patient treated. Admittedly, the major drawback of simulation is the cost, both from the initial investment for the simulator but also for each individual model, which must be custom-made for each patient. Development of more cost-effective 3D printing and simulation devices are needed. With a plethora of new devices and the increased number of operators decreasing the experience for endovascular treatment of IAs, the use of simulation will likely help to achieve and maintain surgical skills and possibly reduce avoidable complications. Patient-specific 3D modeling, treatment simulation, and rehearsal are valid strategies for preoperative planning in the treatment of complex aneurysms, especially in the pediatric population.

\section{Acknowledgments}

We thank the Hall-Halliburton Foundation, Inc., for their donation of the replicator system model (Vascular Simulations). Dr. Santos is sponsored by an Interline Endowment grant.

\section{References}

1. Aeron G, Abruzzo TA, Jones BV: Clinical and imaging features of intracranial arterial aneurysms in the pediatric population. Radiographics 32:667-681, 2012

2. Barburoglu M, Arat A: Flow diverters in the treatment of pediatric cerebrovascular diseases. AJNR Am J Neuroradiol 38:113-118, 2017

3. de Oliveira MMR, Ferrarez CE, Ramos TM, Malheiros JA, Nicolato A, Machado CJ, et al: Learning brain aneurysm microsurgical skills in a human placenta model: predictive validity. J Neurosurg 128:846-852, 2018

4. Duckworth EA, Nickele C, Hoit D, Belayev A, Moran CJ, Arthur AS: The first North American use of the Pipeline Flex flow diverter. BMJ Case Rep 2015:bcr2014011548, 2015

5. Gmeiner M, Dirnberger J, Fenz W, Gollwitzer M, Wurm G, Trenkler J, et al: Virtual cerebral aneurysm clipping with real-time haptic force feedback in neurosurgical education. World Neurosurg 112:e313-e323, 2018

6. Ishibashi T, Takao H, Suzuki T, Yuki I, Kaku S, Kan I, et al: Tailor-made shaping of microcatheters using three-dimensional printed vessel models for endovascular coil embolization. Comput Biol Med 77:59-63, 2016

7. Kimura T, Morita A, Nishimura K, Aiyama H, Itoh $\mathrm{H}, \mathrm{Fu}-$ kaya S, et al: Simulation of and training for cerebral aneurysm clipping with 3-dimensional models. Neurosurgery 65:719-726, 2009

8. Kono K, Shintani A, Okada H, Terada T: Preoperative simulations of endovascular treatment for a cerebral aneurysm using a patient-specific vascular silicone model. Neurol Med Chir (Tokyo) 53:347-351, 2013

9. Marinho P, Vermandel M, Bourgeois P, Lejeune JP, Mordon $\mathrm{S}$, Thines L: Preoperative simulation for the planning of microsurgical clipping of intracranial aneurysms. Simul Healthc 9:370-376, 2014

10. Mashiko T, Otani K, Kawano R, Konno T, Kaneko N, Ito Y, et al: Development of three-dimensional hollow elastic model for cerebral aneurysm clipping simulation enabling rapid and low cost prototyping. World Neurosurg 83:351-361, 2015

11. Miranpuri AS, Nickele CM, Akture E, Royalty K, Niemann DB: Neuroangiography simulation using a silicone model in the angiography suite improves trainee skills. J Neurointerv Surg 6:561-564, 2014

12. Miskovic D, Wyles SM, Ni M, Darzi AW, Hanna GB: Systematic review on mentoring and simulation in laparoscopic colorectal surgery. Ann Surg 252:943-951, 2010

13. Namba K, Higaki A, Kaneko N, Mashiko T, Nemoto S, Watanabe E: Microcatheter shaping for intracranial aneurysm coiling using the 3 -dimensional printing rapid prototyping technology: preliminary result in the first 10 consecutive cases. World Neurosurg 84:178-186, 2015

14. Navarro R, Brown BL, Beier A, Ranalli N, Aldana P, Hanel RA: Flow diversion for complex intracranial aneurysms in young children. J Neurosurg Pediatr 15:276-281, 2015

15. Oliveira Magaldi M, Nicolato A, Godinho JV, Santos M, Prosdocimi A, Malheiros JA, et al: Human placenta aneurysm model for training neurosurgeons in vascular microsurgery. Neurosurgery 10 (Suppl 4):592-601, 2014

16. Pacca P, Jhawar SS, Seclen DV, Wang E, Snyderman C, Gardner PA, et al: "Live cadaver" model for internal carotid artery injury simulation in endoscopic endonasal skull base surgery. Oper Neurosurg (Hagerstown) 13:732-738, 2017

17. Reznick RK, MacRae H: Teaching surgical skills-changes in the wind. N Engl J Med 355:2664-2669, 2006

18. Ribeiro de Oliveira MM, Nicolato A, Santos M, Godinho JV, Brito R, Alvarenga A, et al: Face, content, and construct validity of human placenta as a haptic training tool in neurointerventional surgery. J Neurosurg 124:1238-1244, 2016

19. Shono N, Kin T, Nomura S, Miyawaki S, Saito T, Imai H, et al: Microsurgery simulator of cerebral aneurysm clipping with interactive cerebral deformation featuring a virtual arachnoid. Oper Neurosurg (Hagerstown) 14:579-589, 2018

20. Sorteberg A, Dahlberg D: Intracranial non-traumatic aneurysms in children and adolescents. Curr Pediatr Rev 9:343-352, 2013

21. Wang L, Ye X, Hao Q, Chen Y, Chen X, Wang H, et al: Com- 
parison of two three-dimensional printed models of complex intracranial aneurysms for surgical simulation. World Neurosurg 103:671-679, 2017

22. Wang L, Ye X, Hao Q, Ma L, Chen X, Wang H, et al: Threedimensional intracranial middle cerebral artery aneurysm models for aneurysm surgery and training. J Clin Neurosci 50:77-82, 2018

23. Zhou G, Su M, Yin YL, Li MH: Complications associated with the use of flow-diverting devices for cerebral aneurysms: a systematic review and meta-analysis. Neurosurg Focus 42(6):E17, 2017

\section{Disclosures}

Ricardo A. Hanel is a consultant for Medtronic, Cerenovus, Elum, Three Rivers Medical, Stryker, Codman, and MicroVention; owns stock in Elum, Three Rivers, Cerebrotech, EndoStream, Synchron, Blockade, Neurvana, and InNeuroCo; and serves on the scientific advisory board of Medina Medical.

\section{Author Contributions}

Conception and design: all authors. Acquisition of data: all authors. Analysis and interpretation of data: all authors. Drafting the article: all authors. Critically revising the article: all authors. Reviewed submitted version of manuscript: all authors. Approved the final version of the manuscript on behalf of all authors: Hanel. Statistical analysis: all authors. Administrative/technical/material support: all authors. Study supervision: all authors.

\section{Correspondence}

Ricardo A. Hanel: Lyerly Neurosurgery, Baptist Neurological Institute, Jacksonville, FL. rhanel@lyerlyneuro.com. 